\title{
Climate change continues to be an issue
}

\author{
As the world recovers from one global crisis, it must steel itself for the coming of a far greater one: the climate \\ crisis. Astronomers and planetary scientists have roles to play as trusted scientific experts, but should seek \\ partnerships with domain experts when venturing outside their areas of knowledge.
}

T he COVID-19 pandemic has been a stark reminder of humanity's close links to the 'natural' world. Despite advanced knowledge of virology, immunology, medicine and crisis response techniques, the human species has experienced more than 4 million deaths following infection by a virus that arose naturally (according to best current knowledge). The situation could have been worse, however, and governments around the world did act to mitigate the impact on lives. These measures set an important precedent for action from civil authorities and international cooperation in the future. It is now clear that another global disaster is heading our way and already making its effects felt: the climate crisis. It is inevitable that global temperatures will rise as a consequence of human pollution of the planet over the last two and a half centuries, and particularly over the last 50 years. "Nature does not bargain and you cannot compromise with the laws of physics," warns climate activist Greta Thunberg.

While the initial efforts of some astrophysicists to model the COVID-19 outbreak were criticized in some quarters, the climates of terrestrial planets is a domain where astronomers and planetary scientists have extensive knowledge and expertise. This provides astronomers with a unique viewpoint on Earth's climate crisis, and we should certainly communicate our understanding of this topic to the wider public, especially given our abundant opportunities to engage in public outreach, appear in the media, and teach hundreds of thousands of students every year. However, we should not overstep the boundaries of our knowledge and risk losing our credibility and that of the message. We are, in general, not steeped in the specifics of Earth's climate change, environmentalism, sustainability, climate policy, politics, and so on, but, being scientists, we can examine the scientific evidence regarding climate change ourselves and select and amplify the most important aspects for the benefit of the public. In a Comment in this issue of Nature Astronomy, communication experts Alison Anderson and Gina Maffey present their advice on how to talk to the people around us about the climate crisis, but without making the faux pas that might undermine the important message.

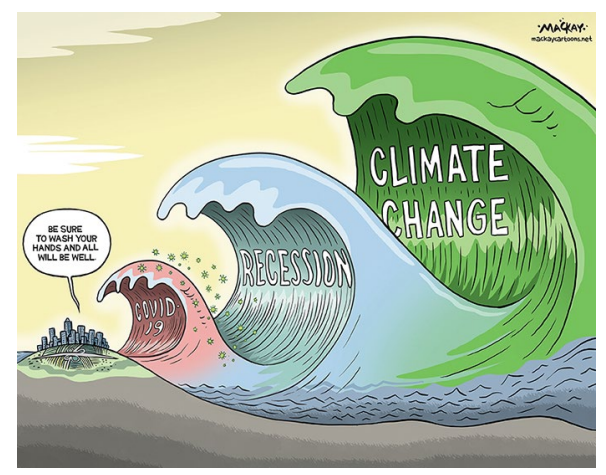

Credit: Artizans.com - Graeme MacKay

It should be stated quite clearly that there is no way to 'fix' the climate crisis. It is unavoidable that the planet will warm, and there will be environmental consequences of that warming: heatwaves, heavy precipitation, droughts, coastal flooding and tropical cyclones. Last month the Intergovernmental Panel on Climate Change released their latest report, which made it clear that there are opportunities to limit the extent of environmental impact if action is taken immediately, though, and future outcomes will depend on the degree of action taken. The report focuses on limiting global cumulative $\mathrm{CO}_{2}$ emissions, reaching at least net zero, and ideally also reducing emissions of other greenhouse gases such as $\mathrm{CH}_{4}$. But it does not explain how to limit $\mathrm{CO}_{2}$ emissions; that will be for governments and intergovernmental organizations to decide. In November this year, hundreds of politicians and world leaders will gather in Glasgow, Scotland, to do just that at the COP26 United Nations Climate Change Conference. At COP21 every country agreed to work together to limit global warming to $1.5^{\circ} \mathrm{C}$ and thus the Paris Agreement was born. COP26 provides countries with an opportunity to update their plans, and Thunberg in particular is urging a radical approach: "The climate and ecological crisis cannot be solved within today's political and economic systems." As global citizens and as scientists, astronomers have two roles through which to encourage their elected representatives to take this radical action. However, in the sometimes-murky world of policy advocacy, it is not always clear how to most effectively propagate change. Former
NATO policy advisor Andrew Williams has distilled his experience in this arena into a Comment in this issue. Again, the advice is to work with the experts.

Exactly a year ago we dedicated our September 2020 issue to presenting the quantitative impact of astronomy as a profession on the environment. Some of the numbers presented in the various articles were surprising: attending a large European astronomy conference generates as much $\mathrm{CO}_{2}$ per capita as a year of everyday life in a developing country; the average Australian astronomer, just through their professional activities, generates $40 \%$ more $\mathrm{CO}_{2}$ than a typical Australian, with senior astronomers being the biggest contributors; and the footprint of European astronomers is not much smaller. These articles and some of the others in the issue raised awareness within the community of astronomy's carbon footprint, and the topic was discussed widely in journal clubs and departmental and board meetings. The Astronomers for Planet Earth group, which was formed off the back of the large European astronomy conference mentioned above, has been keeping the momentum going, engaging in a number of activities detailed in another Comment in the current issue. Organizations such as the European Southern Observatory and the Square Kilometre Array Observatory have been putting forth their sustainability plans. Professional astronomy can exist in a low-carbon future, but changes must be made, from removing the dependence of our observatories and supercomputers on fossil fuels, to cutting the number and extent of flights that we take to attend conferences. With public awareness of the climate crisis growing, and governments meeting to make crucial decisions about our global environmental future, we must use our unique perspective as astronomers and planetary scientists to communicate the scientific facts to the public and stakeholders alike, and work with experts to maximize the credibility and impact of the critical message that disaster is coming, but there is still time to mitigate the extent if action is taken now.

Published online: 15 September 2021 https://doi.org/10.1038/s41550-021-01500-2 